\section{"Cesárea? Não, Obrigada!": ativismo em uma comunidade online na busca pelo parto normal no Brasil}

\author{
"C-section? Thanks, But No Thanks!": activism in an \\ online community in quest for normal childbirth \\ in Brazil
}

“¿Cesárea? ¡No, Gracias!": activismo en una comunidad en línea en la búsqueda de parto natural en Brasil
Gabriela Macedo Hugues 1,2

Maria Luiza Heilborn 1

\section{Resumo}

Este artigo visa a compreender a organização de uma comunidade online cujo objetivo é contribuir para a conquista do parto normal e humanizado entre mulheres de camadas médias. Realizou-se uma netnografia na comunidade Cesárea? Não, Obrigada! na rede social Facebook, cujas participantes são de diferentes partes do país. A análise enfoca a troca de saberes, apoio mútuo entre as participantes sobre o que denominam de processo de "empoderamento" e mudanças na relação médico/paciente. Categorizou-se quatro perfis de participantes: não iniciadas, iniciadas, paciente informada e profissional de saúde. Nas razões das usuárias para a busca de informações online alinhamse interesse pela autonomia de decisão, cuidado e humanização da assistência. A comunidade contribui para esse processo ao organizar, educar e fornecer ferramentas para transformar as participantes em pacientes informadas.

Parto Normal; Humanização da Assistência; Rede Social Online;

Educação de Pacientes como Assunto; Antropologia Cultural

\author{
Correspondência \\ G. M. Hugues \\ Instituto de Medicina Social, Universidade do Estado do \\ Rio de Janeiro \\ Rua São Francisco Xavier 524, Bloco E, 7o andar, Rio de Janeiro, \\ RJ 20550-013, Brasil. \\ gabrielahugues@uol.com.br \\ 1 Instituto de Medicina Social, Universidade do Estado do Rio de \\ Janeiro, Rio de Janeiro, Brasil. \\ 2 Universidade de São Paulo, São Paulo, São Paulo, Brasil.
}




\section{Introdução}

A interação social mediada por computadores cria realidades impossíveis e inexistentes na sociabilidade face a face, pois prescinde de territorialidade. $\mathrm{O}$ mundo virtual conecta pessoas que desejam trocar experiências sobre certos tópicos que não poderiam fazê-lo em seus locais de convívio social. As redes sociais inseridas e incorporadas ao cotidiano 1 criam grupos de discussão não limitados pelo espaço físico e permitem a conexão de pessoas distantes, evidenciando a amplitude social de determinados fenômenos e permitindo que indivíduos se descolem das suas redes tradicionais de sociabilidade e apoio.

No Brasil, ao longo dos anos houve um aumento expressivo das taxas de cesarianas (Ministério da Saúde. Portal da Saúde: SINASC. http://tabnet.datasus.gov.br/cgi/deftohtm.exe?sinasc/cnv/nvuf.def, acessado em 15/Jan/2018). Contudo, houve também o fortalecimento de um movimento de mulheres por meio da Internet e das redes sociais como Orkut e Facebook em busca de informações sobre gestação e parto. Os espaços de comunicação online transformaram-se em ferramentas essenciais para a divulgação, a troca de informações e para a reunião daquelas que almejam partos normais. O resultado dessas interações é aquele denominado por Lévy ${ }^{2}$ como inteligência coletiva, que passa a ser condição basilar para impelir os serviços de saúde a reverter as taxas de cesariana a partir da pressão de mulheres. Aquelas informações, em certa medida eram disponíveis na rede, mas não necessariamente chegavam à mulher grávida interessada em ter acesso ao parto normal "respeitoso" - categoria nativa utilizada em grupos de Internet - passaram a ser mais disseminadas nos meios virtuais.

\section{Parto humanizado}

O parto humanizado é entendido como aquele que atende aos anseios expressos pelas mulheres dessa comunidade virtual. Geralmente não há nesse contexto desejo pela cesariana eletiva. Os projetos das gestantes ou das mães são orientados pela positivação da agência pessoal na decisão do plano de parto. Recusam, assim, procedimentos considerados desnecessários e/ou iatrogênicos para a garantia de uma parição segura. Compreendemos, portanto, o parto humanizado como aquele que expressa tal postura como a interseção entre autonomia da mulher como protagonista do evento, poder de decisão sobre seu corpo e parto, e a presença de uma equipe de cuidado, adepta do modelo humanista descrito por Davis-Floyd ${ }^{3}$ e Davis-Floyd \& St. John ${ }^{4}$. Tal modelo apoia-se na medicina baseada em evidências como respaldo da prática clínica. A tecnologia não é banida, e sim pautada na medicina baseada em evidências científicas e usada conforme a anuência da gestante. Trata-se de uma resposta à excessiva medicalização do parto que denota o valor conferido à tomada de decisão sobre seus corpos.

Embora a Medicina Baseada em Evidências receba diversas críticas quanto ao engessamento de práticas, protocolos que não contemplam todas as situações e "transforma o médico em um seguidor de esquemas" 5 (p. 2244), em Obstetrícia a perspectiva crítica de gênero é crucial 6. Gênero na análise sobre saúde implica reconhecer as relações assimétricas entre homens e mulheres, como também entre profissionais e pessoas leigas 7 . Seguir evidências científicas e praticar assistência nelas baseadas, adotando as Boas Práticas segundo a Organização Mundial da Saúde (OMS) 8, é medida protetiva contra procedimentos considerados iatrogênicos, que exercem um controle exacerbado sobre o parto que, na maioria das vezes, é um processo fisiológico. Não se pode negar a expressividade de trabalhos científicos que apontam como o corpo feminino e o sujeito-mulher foram subalternizados pela prática médica na construção e exercício da Ginecologia e da Obstetrícia 3,9,10,11.

Com base em relatos de parto na mencionada comunidade e em questionamentos sobre os motivos acionados pelos médicos para levá-las a cesáreas eletivas ou intraparto, salientou-se o movimento de ajuda entre mulheres. Delineamento de estratégias, difusão de artigos científicos, vídeos de parto e protocolos de atendimento são fontes de informação para que as usuárias da comunidade alcancem o objetivo: parto normal com bebê saudável e cesárea apenas se for necessária. A comunidade Cesárea? Não, Obrigada! (https://www.facebook.com/groups/cesareanao) visa a controlar o "abuso de poder médico" sobre corpos e vontades. É possível usar a imagem de uma pequena insurreição feminina não necessariamente feminista, porquanto nem todas as usuárias identificam-se com este movimento - contra o sistema tecnocrata "cesarista" vigente, como possibilidade de resistência das mulheres aos tratamentos "que as oprimem" 10 , seja cesariana sem indicação, seja parto violento. 
Por parto violento compreende-se aquele que utiliza intervenções como o uso de ocitocina sintética sem indicação clínica, instalada apenas para acelerar o tempo de trabalho de parto; a posição litotômica para parir; os puxos dirigidos; a episiotomia, por vezes feita sem anestesia; a manobra de Kristeller 12. Pelo princípio ético da não-maleficência - primum non nocere: primeiro, não causar dano - tais procedimentos ditos de rotina médica resultam em efeitos nocivos para as parturientes e para os bebês. Essas mulheres que escolhem o parto normal, em sua maioria têm gestações de risco habitual, mas não o desejam a qualquer custo. A percepção de que houve uma cesárea bem indicada é aceita e bem-vinda.

\section{Metodologia da pesquisa}

Utilizamos o método netnográfico, termo cunhado por Kozinets ${ }^{13}$, no qual a observação participante e a etnografia clássica são adaptadas ao uso da tecnologia da informação da comunicação mediada por computadores. Tal procedimento foi distribuído em três etapas: observação participante, levantamento e mapeamento da comunidade, e análise de narrativas. As etapas e procedimentos metodológicos recomendados 13 para planejamento e execução foram seguidos pela primeira autora: entrada na rede com base no conhecimento da comunidade a ser estudada, especificação do tipo de participante, garantia de confidencialidade e anonimato; carta de anuência da criadora da comunidade para observação; apresentação da pesquisa à comunidade, conforme exigência do Comitê de Ética em Pesquisa do Instituto de Medicina Social da Universidade do Estado do Rio de Janeiro (parecer no 2.095.858); coleta e análise de dados. O objetivo consistia em manter a postura de estranhamento em relação ao objeto de estudo. Em um primeiro momento, o afastamento total na interação com a comunidade foi estratégico para que pudéssemos ser capazes de ler tais processos na tentativa de traduzi-los e interpretá-los. Para Gilberto Velho, o pesquisador pode estar acostumado à "paisagem social onde a disposição de atores me é familiar... no entanto, isso não significa que eu compreenda a lógica de suas relações" 14 (p. 128). Ao estudar um grupo que nos é próximo, poderíamos cair na armadilha de naturalizar situações cujo estranhamento deveria ser mantido para análise. O distanciamento foi crucial na segunda etapa da pesquisa, cujos resultados apresentamos neste artigo.

A observação do grupo ocorreu entre agosto de 2016 e janeiro de 2018. Foi realizada pesquisa sistemática diária durante os meses de junho e julho de 2017. Junho foi dedicado à observação e coleta de dados e julho à checagem de padrão do mês anterior, se era mantido ou não. Tal critério possibilitou identificar a validez de insights e descobertas, especialmente aquelas relacionadas a conflitos. No seguimento cotidiano dos primeiros 30 dias foram analisados o número de participantes que entraram na comunidade, os perfis privados e verificados todos os tópicos publicados a cada dia. O objetivo era a eleição de temas; ocorrência de repetição e sua frequência. Em junho de 2017, quase 1.500 pessoas entraram na comunidade Cesárea? Não, Obrigada!. Foram publicados 433 novos tópicos. Os dias de quintas e sextas-feiras foram os de maior atividade, tanto em publicação de novos tópicos quanto em comentários em discussões prévias. Em vésperas de feriados ocorreu o mesmo incremento na participação. Nos dois meses examinados houve uma série de perguntas cujas repostas serão abordadas no tópico de regras da comunidade, o qual é afixado como o primeiro da página. As regras não são lidas por muitas participantes.

A regularidade da observação foi essencial para o distanciamento, tornando-se clara a distribuição dos interesses e para a identificar como e onde surgem os conflitos e quais são as questões recorrentes. Dos 433 novos tópicos publicados no mês de junho, a maioria (62\%) foi relacionada a parto. Todos os dias havia novos relatos de como "enfrentaram e venceram o sistema" ou de como "o sistema luta contra você”. Há pouca reflexão sobre gestação e pré-natal - um possível indício de maior necessidade de informação sobre este período. Essa observação advém do fato de uma das autoras deste artigo ser profissional de saúde dedicada ao tema e cuja prática profissional a faz pensar sobre como as mulheres que buscam parto "respeitoso" dedicam mais tempo à informação sobre parto em si e menos sobre pré-natal. Durante a gestação não é incomum a mulher que deseja o parto normal mudar de ideia e partir para a cesariana, como indicaram Domingues et al. 15. Portanto, é o momento crucial para o processo de tomada de decisão. 
Das poucas publicações sobre o período gestacional na comunidade (17\% do total), algumas abordam questões pontuais e simples, em geral sobre contrações de Braxton-Hicks - as chamadas contrações de treinamento - e outras sobre ultrassonografia e o sentimento de ansiedade que este exame produz. Muitas mulheres acreditam que a ultrassonografia serve para observar o bem-estar fetal, mas reiteradamente relatam ansiedade, medo e desconfiança com o resultado. A partir da apreensão, sobrevém a procura por apoio no grupo como tentativa de abrandar o sentimento, já que nas relações off-line as concepções sobre a noção de risco podem ser exacerbadas ou apenas equivocadas. Solicitações de indicação de médicos formam $8 \%$ das publicações e são perpassadas por dicas e considerações sobre deixar o plano de saúde para parir no Sistema Único de Saúde (SUS). Temas sobre amamentação e pós-parto aparecem em 5\% das discussões e os diálogos se repetem: as participantes indicam grupos de amamentação, mas ajudam com orientações básicas. Há 8\% de publicações de cunho jocoso, vídeos, reportagens sobre celebridades que deram à luz.

\section{Panorama da comunidade}

Cesárea? Não, Obrigada! é um grupo de discussão sobre gravidez, parto e puerpério criado em 2012 no Facebook pela doula e ativista do parto humanizado Ingrid Lotfi. A versão original constou de outra rede de relacionamentos, o Orkut, nos anos 2000 até sua extinção em 2014. A moderação do conteúdo postado é dividida entre profissionais ligadas ao parto: doulas, médicas, obstetrizes ou enfermeiras obstetras, ativistas e pacientes informadas. A aprovação de tópicos e membros conta com sete mulheres e, dentre elas, cinco profissionais, entretanto, não é fixa. Quando os tópicos são liberados ao público, as próprias participantes dialogam sobre o tema. As profissionais da moderação comparecem para responder desde perguntas técnicas a problemas de comunicação. Com aproximadamente 40 mil membros em junho de 2019, pauta-se na "defesa do parto natural e humanizado, com foco no protagonismo feminino nas tomadas de decisão" (trecho da descrição pública da comunidade Cesárea? Não, Obrigada!). Portanto, por ser um espaço de defesa do parto normal e da autonomia feminina, tem como característica não contar entre seus membros com mulheres que preferem cesariana eletiva sem indicação clínica. Há pouquíssimos homens, caracterizados pela baixa participação. No entanto, dois médicos obstetras têm participação significativa ao comentar sobre evidências científicas: um do Estado de São Paulo e outro do Rio de Janeiro.

Trata-se, assim, de uma iniciativa cujo objetivo é propagar "informação de qualidade" às mulheres que possuem uma atitude proativa em direção à autonomia de escolha na busca pelo parto "respeitoso". Comenta-se muito na comunidade sobre haver um intervalo de tempo de nove meses para se formar em Obstetrícia e não ser levada à cesariana por conveniência médica: um convite a mulheres que querem exercer autonomia de cuidado da gestação e parto a se transformarem em pacientes informadas, promovendo um desenvolvimento de capacidades em relação ao período gravídico-puerperal.

Na comunidade em análise há um subgrupo de participantes que usufrui de planos privados de saúde. Durante a gravidez ou na hora do parto, trocam o atendimento particular via saúde suplementar pela atenção ao parto em hospital público em inúmeras cidades do Brasil. Elas postam narrativas detalhadas dos partos, abordam questões íntimas nesse espaço virtual e discutem estratégias sobre qual o melhor momento para a internação, qual o papel de uma doula, como contratá-la, quais intercorrências possíveis e mais comuns. Essas iniciativas exprimem a vontade de alcançar um parto "respeitoso", mesmo que o desfecho final seja a cesariana.

\section{Leiam as regras! Como a Cesárea? Não, Obrigada! se organiza}

Comunidade de tipo semiprivada ou fechada, pode ser encontrada por qualquer pessoa a partir de uma busca na rede, mas a participação depende do aval da equipe moderadora. O conteúdo, portanto, não pode ser acessado por não integrantes. A escolha pela privacidade é sustentada em alguns objetivos: atrair participantes que escolhem/desejam parto normal; afastar pessoas que fazem apologia à cesariana; filtrar perfis falsos, perfis de vendedores, além de assediadores e pedófilos; evitar que sejam feitos capturas de imagem por pessoas cujas ideias não se coadunam com o ideário de parto humanizado. 
As moderadoras permitem a entrada de todos os perfis a princípio verdadeiros e evitam perfis falsos - por exemplo, com a utilização de nomes e/ou fotos de celebridades ou pessoas notórias. Os pedidos de entrada na comunidade são volumosos e as candidatas à participante passaram a responder quatro perguntas para a aprovação de entrada. São elas: qual o interesse no grupo?; qual a ligação com o universo do parto humanizado?; se sabem fazer buscas na lupa da rede social; se compreendem que antes de fazer uma pergunta devem procurar na lupa para verificar se o assunto foi abordado previamente.

Essas perguntas possivelmente coíbem as desavisadas. É provável que haja alguns defensores da cesariana entre quem está no grupo, mas devem apenas ler em modo silencioso, o participante chamado lurker. Alguns conflitos com mulheres advogando em prol da cesárea eletiva sem indicação clínica ocorriam com alguma frequência no passado, mas aos poucos foram deixando de existir. $\mathrm{O}$ fito da comunidade Cesárea? Não, Obrigada! não é o embate parto normal versus cesariana e sim a autonomia da mulher na escolha da modalidade de parto e como alcançar este objetivo. Quando o perfil de pessoa engajada na apologia da cesariana aparece na comunidade, as próprias usuárias denunciam, chamam a moderação e a participante é excluída. Atualmente, os conflitos sobre a cesariana aparecem de modo esparso.

Na página inicial da comunidade, a foto de capa mostrava um bebê com expressão irritada seguida da legenda em caixa alta: “LEIAM AS REGRAS!". Imagem que denota uma tentativa de organizar, educar e fornecer ferramentas para que as integrantes possam se transformar em pacientes informadas e que facilita a busca das usuárias em relação às dúvidas frequentes, já respondidas, tanto por profissionais quanto por outras participantes. Essas regras estão em um documento - o primeiro tópico da página do grupo foi escrito em fevereiro de 2013, quando a comunidade ganhou um tamanho expressivo, e foi editado em 2 de janeiro de 2018. A edição do documento passou a incluir uma nova regra, que interdita postagens nas quais as mulheres sejam tratadas por diminutivos, tais como "gravidinha", "mãezinha" ou qualquer termo infantilizador.

Ao final do tópico de regras de boa convivência e organização da comunidade Cesárea? Não, Obrigada! há uma lista de links com respostas para dúvidas. Não é possível asseverar a efetividade da leitura. Pelas perguntas surgidas diariamente, há indícios de que uma boa parcela daquelas que abrem tópicos não leu ou gostaria de ter uma reposta para um item específico. Assim, questões bem recentes, muitas vezes tratadas no dia anterior, são publicadas, apesar da suposta facilidade em acessar os links reunidos em um único tópico. A equipe de moderação aspira uma conduta da parte das usuárias que está longe de ser obtida. $\mathrm{O}$ volume de postagens é alto durante todos os dias. Composta por quarenta e cinco itens, a lista contém temas informativos e formativos. Esses abordam assuntos relacionados ao pré-natal, doenças e intercorrências durante a gestação e parto, parto, pós-parto e "outros" (Quadro 1). Questionamentos recorrentes e respondidos são: como fazer plano de parto?, quais os sinais de trabalho de parto?, além de perguntas sobre algumas patologias da gestação respondidas por vários profissionais de saúde que anexam evidências científicas para sustentar seus pontos de vista.

Após alguns conflitos deflagrados durante o mês de dezembro de 2017, houve mudanças na comunidade em janeiro de 2018. O estopim foi o descumprimento das regras, como informações sobre exames desnecessários durante o pré-natal de risco habitual. Uma das participantes insistia na necessidade de fazê-lo, mesmo que inúmeros profissionais de saúde negassem e indicassem artigos científicos com evidências para leitura.

A foto da capa foi alterada (Figura 1), para favorecer uma melhor visualização do resumo das regras.

É possível que a moderação tenha adotado novas regras para afastar participantes que discordam delas. Notou-se uma pequena diminuição de membros no dia em que a foto de capa foi modificada. 
Quadro 1

Temas e tópicos fixos da comunidade Cesárea? Não, Obrigada!.

\begin{tabular}{|c|c|}
\hline TEMAS & TÓPICOS \\
\hline \multirow[t]{7}{*}{ Pré-natal } & Circular de cordão \\
\hline & Gestação de alto risco \\
\hline & Gestação prolongada \\
\hline & Líquido amniótico \\
\hline & Pélvico/Versão cefálica externa \\
\hline & Ultrassonografias \\
\hline & Ultrassom do coração fetal \\
\hline \multirow[t]{9}{*}{ Doenças e intercorrências na gestação e parto } & Diabetes gestacional \\
\hline & Exames de rotina de pré-natal \\
\hline & Herpes genital e gestação \\
\hline & Inserção velamentosa e vasa prévia \\
\hline & Placenta prévia \\
\hline & Pressão alta \\
\hline & Sangramento da primeira metade da gestação \\
\hline & Síndrome HELLP \\
\hline & Streptococcus/Estreptococo do grupo B \\
\hline \multirow[t]{17}{*}{ Parto } & Acretismo placentário \\
\hline & Analgesia de parto \\
\hline & Bolsa rota \\
\hline & Clampeamento/Coleta de sangue de cordão \\
\hline & Desproporção céfalo-pélvica \\
\hline & Episiotomia \\
\hline & Fases e sinais de trabalho de parto \\
\hline & Hemorragia pós-parto \\
\hline & Indicações de cesariana \\
\hline & Indução \\
\hline & Mecônio \\
\hline & Parto domiciliar \\
\hline & Parto pelo plano de saúde \\
\hline & Proteção perineal \\
\hline & Puxo dirigido \\
\hline & Tampão mucoso \\
\hline & VBAC \\
\hline Pós-parto & Indicações sobre amamentação \\
\hline \multirow[t]{11}{*}{ Outros } & Doulas \\
\hline & Doulas e enfermeiros no parto \\
\hline & Doulas voluntárias \\
\hline & Evidências científicas: o que são? \\
\hline & Glossário do parto \\
\hline & Livros sobre gestação e nascimento \\
\hline & Mitos sobre causas de aborto e parto prematuro \\
\hline & Taxas de cesariana de médicos de planos de saúde \\
\hline & Vaquinhas para parto (arrecadação de dinheiro) \\
\hline & Vídeos de parto \\
\hline & Violência obstétrica \\
\hline
\end{tabular}

VBAC: vaginal birth after caesarean (sigla em inglês para parto normal após cesariana) 


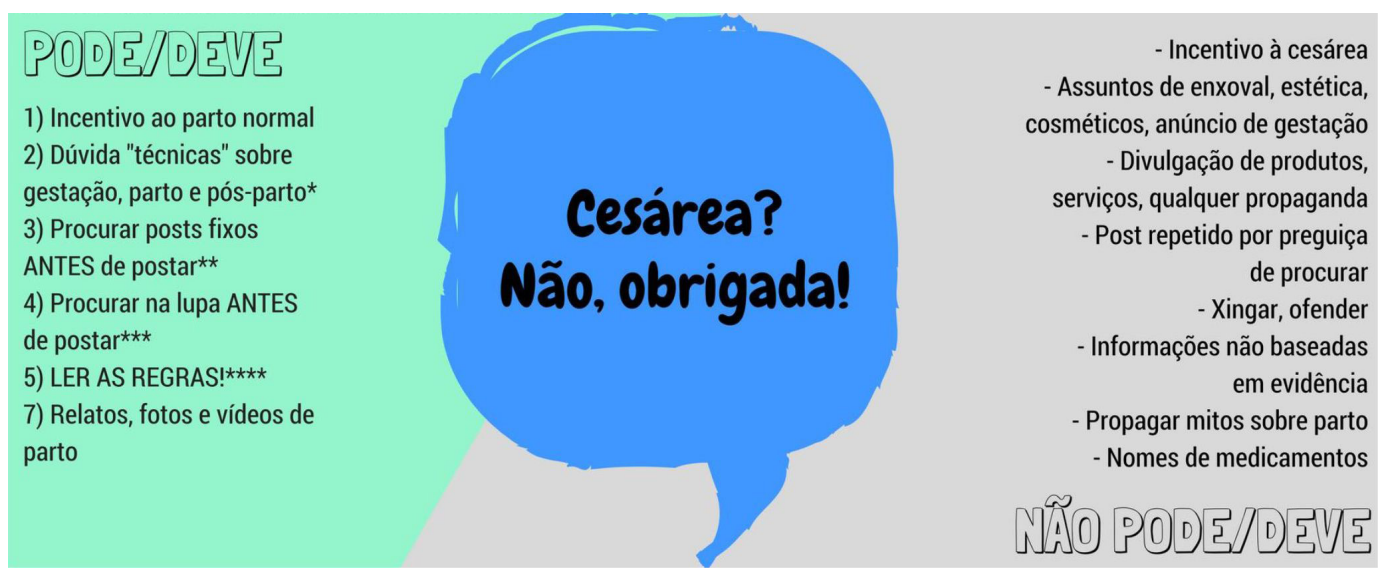

Fonte: Comunidade Cesárea? Não, Obrigada! (https://www.facebook.com/groups/cesareanao/).

\section{As usuárias da comunidade Cesárea? Não, Obrigada!: não iniciadas, iniciadas, paciente informada e profissional de saúde}

As mulheres que buscam essa comunidade têm como traço comum o desejo pelo parto normal humanizado. As adeptas desse modelo de parturição não necessariamente se autoidentificam como feministas. Feminismo e maternidade não traduzem experiências comuns, antes falam de modos peculiares de visão de mundo 16,17. Entretanto, a moderação tem uma atuação ativista, feminista e defensora dos direitos sexuais e reprodutivos.

As usuárias do fórum questionam sobre como alcançar o parto por elas decidido, sem cair no que elas denominam de "o conto da cesárea" e sobre a dificuldade inerente de estar grávida em um país cujo nascimento por via cirúrgica supera o nascimento por via baixa. As participantes oferecem percepções pessoais e dividem suas histórias ao narrar seus partos, conquistas, angústias e medos. Os relatos de parto são uma prática social que representa modos de ser e agir, cujo fito é o autoconhecimento ou o apoio a outras mulheres. As interações na comunidade Cesárea? Não, Obrigada! revelam algo além de conselhos técnicos, troca de informações; elas demonstram um alto grau de consciência do sistema de nascimento predominante no Brasil, no qual decisões são tomadas pelo médico, o parto é visto como patológico $18 \mathrm{e}$ a cesariana se destaca como modo de nascer 19.

A comunidade torna-se um espaço de troca e de encontro com pares, pessoas que viveram ou estão vivenciando a mesma experiência de gestação e escolha pelo parto normal. Inúmeras vezes a família percebe a cesariana como o procedimento mais seguro pois implica o uso de mais tecnologia. Ao longo da pesquisa, foram identificadas algumas mulheres que declararam estar nas últimas semanas de gestação em busca do parto normal e que saem da comunidade semanas depois. É provável que essas não tenham conseguido o parto por algum motivo, possivelmente sem uma indicação clínica clara, e se desligam sem fazer alarde. São mulheres com baixa participação, as quais só se pôde perceber a saída com base em inúmeras leituras dos mesmos tópicos durante os dois meses de observação.

Quatro perfis de usuárias destacam-se:

(a) Não iniciadas (NI): geralmente primigestas e leigas que desejam em intensidades variáveis um parto normal ou aquelas que não querem uma cesariana, uma manifestação de desejo distinta da primeira - ou ainda aquelas que estão desconfiadas das intenções dos obstetras, pois sabem que é difícil fugir de uma cesariana no Brasil. Em geral não sabem onde ou como buscar informação de qualidade. 
Várias dessas usuárias procuram o grupo no final da gestação, quando o médico, mormente do sistema suplementar de saúde, indica uma cesariana eletiva por algum motivo com o qual elas não concordam ou que as faz desconfiar. Algumas declaram sentimentos de medo e/ou ansiedade em relação à gestação e ao parto. São aquelas que mais expressam questionamentos e acumulam perguntas básicas já respondidas diária e prontamente por várias mulheres e, às vezes, por alguns profissionais.

(b) Iniciadas (I): mulheres que são mães ou que já acompanharam gestações de perto e se informaram minimamente. Mostram algum conhecimento sobre o universo da gestação e do parto. Necessariamente não têm conhecimento técnico, mas viveram na prática uma gestação e um parto. Em geral são as que conseguiram parir ou pelo menos entraram em trabalho de parto e, portanto, têm conhecimento empírico sobre eventos e situações que ocorrem na gestação, como, por exemplo, o que é tampão mucoso. Participam ativamente e são bastante entusiastas.

(c) Paciente informada (PI): a troca de informações é o primeiro passo para se transformar em paciente informada. O perfil da paciente informada é variado e comporta desde a mulher que foi submetida a pelo menos uma cesárea, passa por aquela que "estudou Obstetrícia antes e/ou durante a gestação" ou sofreu violência obstétrica durante o parto, a profissional de saúde que sabe ler evidências científicas, como farmacêuticas, enfermeiras e dentistas, para citar apenas um conjunto das integrantes da categoria "paciente informada profissionais". Não é possível dizer que toda mulher que teve cesariana tornar-se-á uma paciente informada, mas inúmeras delas transformam-se a partir da busca por respostas para as cesáreas às quais foram submetidas. A paciente informada é aquela pessoa que conquistou habilidades e conhecimentos necessários para desempenhar um papel ativo no processo de decisão envolvendo sua saúde e a gestão de suas condições de vida, sem sair, no entanto, da abordagem biomédica 20. A partir dessas características pode-se discutir se há a promoção do empoderamento da mulher ou se a hegemonia dos saberes biomédicos é ampliada. Questionamos se o processo de empoderamento não é uma outra face desse discurso, na medida em que as mulheres sentem necessidade de se apropriar de saberes biomédicos para conseguirem o parto desejado. Não basta querer o parto, é necessário saber como obtê-lo por meio do estudo das práticas obstétricas.

(d) Profissionais da assistência ao parto (P): obstetras, enfermeiras-obstetras, obstetrizes e pediatras que respondem às perguntas, postam, traduzem e esmiúçam evidências científicas para uma linguagem acessível a leigos. Parte desse conjunto de profissionais é composto pelas moderadoras, mas não apenas. Outras profissionais participam do debate, respondem a questionamentos e estão envolvidas na dinâmica da comunidade.

A seguir, alguns diálogos que ilustram os quatro conjuntos de integrantes da comunidade Cesárea? Não, Obrigada! e como se relacionam entre si:

\section{- Diálogo 1}

NI: "Como e onde é a dor da contração?"

I1: "Você vai saber reconhecer. Pode acreditar".

I2: "A verdadeira contração a barriga endurece, fica como pedra, vem uma dor ardida das costas pra barriga, como se estivesse 'abrindo' a lombar, é uma dor incomparável, difícil de explicar, só sentindo mesmo pra entender".

\section{- Diálogo 2}

NI: "Estou de 24 semanas e meu bebê está sentado. Até quando ele vira sozinho?"

I1: "Ele ainda vai mudar muito de posição! Não se preocupe".

I2: "Com 24 semanas e já está [o médico] fazendo terrorismo? Corre para as colinas!".

PI: "Caso o bebê esteja pélvico [sentado] você tem 3 opções: procurar uma equipe que acompanhe um parto pélvico, tentar a manobra chamada versão cefálica externa ou esperar entrar em trabalho de parto e só depois fazer a cesárea, de qualquer forma o ideal é esperar entrar em trabalho de parto! Lembre também que no dia do parto nós saímos do nosso 'normal', então procure mostrar as informações para o seu acompanhante também, porque caso seja necessário é ele quem vai 'brigar' por você!"

P: "Até agora as evidências apontam para uma segurança maior na VCE [versão cefálica externa] sobre o parto vaginal pélvico, embora o parto seja muito seguro [risco baixo de complicação]. Parece que o trabalho do Louwen et al. 21 derruba essa afirmação, mas ainda temos que aguardar a publicação e estudá-la". 


\section{A linguagem do parto}

A comunidade Cesárea? Não, Obrigada! declara-se um grupo ativista e, como tal, pressupostos do movimento de humanização do parto são debatidos no grupo. Um deles diz respeito à nomenclatura relacionada ao parto. Uma das questões centrais quanto à nomenclatura para ativistas é a nomeação da cirurgia cesariana. Como essa cirurgia representou 52\% dos nascimentos no Brasil e quase $90 \%$ dos nascimentos por meio de pagamento privado - via plano de saúde - em 2012 16, seu crescimento histórico desde a década de 1990 tem trazido consequências: dentre elas, a normalização e legitimação do uso dessa cirurgia como modo de nascer, representando o modo "normal" de dar à luz 20. Sendo assim, ao longo dos anos, de cesariana ou cesárea, esse procedimento passou a ser chamado de "parto cesáreo", "parto cesariana" sem, no entanto, ter havido quaisquer modificações significativas durante o procedimento em si, apenas uma mudança linguística. Nas palavras de uma participante da Cesárea? Não, Obrigada! em debate sobre a via de nascimento e sua nomenclatura: "Discordo de quem acha o debate sobre afirmar as diferenças é desnecessário. Enquanto cesárea for vista como parto/parir, ela ganha status de tanto faz em relação ao parto normal. E sabemos que não é bem assim". Outra participante comenta: "O problema em chamar cesárea de parto é que faz um procedimento cirúrgico parecer normal, natural, simples. Quando você fala que precisa fazer uma cirurgia, todos ficam preocupados, afinal, existem riscos! A não ser que seja cesárea. Aí não é cirurgia, é parto".

Para as ativistas em prol da humanização do parto é necessário manter a distinção linguística, demarcar limites entre o processo natural e o cirúrgico. A dicotomia natureza/parto-cultura/cesariana é enfatizada e, portanto, caracterizar a cirurgia como parto é visto pelo ativismo como um modo de suavizar o que de fato é essa via de nascimento: um ato cirúrgico que, em princípio, tem o objetivo de salvar vidas.

"No Brasil, costumamos substituir palavras por outras, às vezes de forma natural [figuras de linguagem]. Hoje em dia tornou-se 'natural' utilizarem a palavra PARTO como se ela significasse 'via de nascimento.' Isso pra se ter um efeito 'mais natural".

"Esse ato de substituirmos uma palavra por outra com sentido de AMENIZAR, suavizar o efeito de 'dor' do real e verdadeiro sentido da palavra é chamado de EUFEMISMO. Por exemplo: [o fulano partiu dessa pra melhor] ao invés de dizer [o fulano morreu]. O parto cesárea ao invés de dizermos A CIRURGIA CESÁREA... Muitas se sentem desconfortáveis em utilizar a palavra 'cirurgia' para uma via de nascimento, pois para muitos parece soar estranho, pesado, algo que deveria ser tão natural como o nascimento. Então, utilizam a palavra que vem de uma fisiologia natural como 'parto' para algo que não deve nunca ser visto como natural".

"Diante desses fatos, devemos nos conscientizar e parar de chamar cesárea de PARTO, ainda somos uma minoria... Mas se nós que somos tão poucos ainda continuarmos dizendo que CESÁREA É PARTO, nós nunca iremos mudar a história do nascimento. Nunca teremos nossos partos respeitados pelos médicos, porque eles mesmos nos indicam outro tipo de 'parto' e nos fazem acreditar que 'parimos".

O texto anterior foi publicado após uma discussão na qual duas mulheres afirmavam que cesárea era parto em outro tópico sobre uma complicação no trabalho de parto. Houve apenas respostas de apoio a ele e entre elas, destaca-se a seguinte: "Perfeito. Eu não tive um parto, por isso mesmo sofro. Qual o sentido de condenar as cesarianas desnecessárias epidêmicas se insistimos em igualá-las ao parto? Se fossem iguais, qual seria o problema de fazer cirurgia a rodo? Se tudo é parto mesmo..." Pode-se discutir se o grupo tem o papel de formatar, normatizar, influenciar e modificar o pensamento em relação ao parto entre as participantes.

\section{Considerações finais}

O método netnográfico 1,14,22 mostrou-se eficaz em um mundo no qual a conectividade é ilimitada. $\mathrm{O}$ discurso online forneceu um panorama para a construção do conhecimento de usuárias do grupo que propicia a transformação da forma como possam fazer valer suas escolhas, sem o óbice da influência presente em pesquisas direcionadas. Apesar de nossos achados não poderem ser generalizados para outras comunidades, as trocas de conhecimento virtuais têm o poder de modificar as percepções daqueles que buscam informações fora das redes de relações face a face. 
No conjunto de grupos de informações existente na Internet, a comunidade Cesárea? Não, Obrigada! permite e incentiva a educação de mulheres sobre autocuidado, gravidez, parto e maternidade. Contribui com ferramentas baseadas em evidências científicas para que seu público possa se educar e se transformar em paciente informada. O objetivo da comunidade é a construção de maior autonomia feminina na escolha do tipo de parto desejado. Ademais, o empoderamento feminino nesse grupo pode ser entendido como um processo no qual às mulheres participantes são apresentadas ferramentas que as permitem adquirir conhecimento e argumentos para se contraporem às relações assimétricas mantidas com médicos para a conquista do parto almejado. Trata-se de um processo de garantir autonomia para as mulheres.

O ativismo político da comunidade Cesárea? Não, Obrigada! orienta-se pela busca de melhora dos indicadores da saúde reprodutiva das mulheres no Brasil. Caracteriza-se como outras redes de diferentes matizes do feminismo brasileiro pela formação profissional e científica das moderadoras $23 \mathrm{e}$ pelo discurso de equidade de gênero e enfrentamento da medicalização excessiva do corpo feminino 12, agora tratado pelo ângulo da valorização do poder decisório das gestantes e parturientes. Por tratar-se de um estudo de caráter (n)etnográfico detalhado, uma possível contribuição deste artigo para o campo da Saúde Coletiva é ilustrar o desenrolar de interações sociais que conduzem à atitude proativa que interfere no comportamento por parte de usuárias do sistema de saúde público ou privado.

\section{Colaboradores}

G. M. Hugues desenvolveu o projeto, coleta, análise e interpretação dos dados, redação e revisão do artigo; aprovou a versão final a ser publicada. M. L. Heilborn orientou todas as etapas do trabalho, participou da revisão e redação do artigo; aprovou a versão final a ser publicada.

\section{Informações adicionais}

ORCID: Gabriela Macedo Hugues (0000-00034646-4313); Maria Luiza Heilborn (0000-00020581-5466).

\section{Agradecimentos}

À Ingrid Lotfi, criadora e coordenadora da comunidade Cesárea? Não, Obrigada! por nos autorizar o estudo. A todas as mulheres participantes do grupo.

\section{Referências}

1. Hine C. Ethnography for the internet: embedded, embodied and everyday. London: Bloomsburry; 2015.

2. Lévy P. A inteligência coletiva: por uma antropologia do ciberespaço. 2a Ed. São Paulo: Loyola; 2003.

3. Davis-Floyd R. Birth as an American rite of passage. 2nd Ed. Berkeley: University of California Press; 2003.

4. Davis-Floyd R, St. John G. From doctor to healer: the transformative journey. 2nd Ed. New Brunswick: Rutgers University Press; 2001.

5. Uchoa SAC, Camargo Júnior KR. Os protocolos e a decisão médica: medicina baseada em vivências e ou evidências? Ciênc Saúde Colet 2010; 15:2241-9.

6. Diniz CSG, Rattner D, d'Oliveira AFPL, Aguiar JM, Niy DY. Disrespect and abuse in childbirth in Brazil: social activism, public policies and providers' training. Reprod Health Matters 2018; 26:19-35.

7. Heilborn ML. Gênero, sexualidade e saúde. In: Silva DPM, organizador. Saúde, sexualidade e reprodução - compartilhando responsabilidades. Rio de Janeiro: EDUERJ; 1997. p. 101-10. 
8. World Health Organization. WHO recommendations: intrapartum care for a positive childbirth experience: web annex. Evidence base. https://apps.who.int/iris/ handle $/ 10665 / 260215$ ?locale-attribute $=$ pt $\&$ (acessado em Jul/2019).

9. Maia MB. Humanização do parto: política pública, comportamento organizacional e ethos profissional. Rio de Janeiro: Editora Fiocruz; 2010.

10. Martin E. A mulher no corpo: uma análise cultural da reprodução. Rio de Janeiro: Garamond; 2006.

11. Rohden F. Uma ciência da diferença: sexo, contracepção e natalidade na medicina da mulher [Tese de Doutorado]. Rio de Janeiro: $\mathrm{Mu}$ seu Nacional, Universidade Federal do Rio de Janeiro; 2000.

12. Diniz CSG. Humanização da Assistência ao parto no Brasil: os muitos sentidos de um movimento. Ciênc Saúde Colet 2005; 10:627-37.

13. Kozinets RV. Netnografia: realizando pesquisa etnográfica online. Porto Alegre: Penso; 2014.

14. Velho, G. Individualismo e cultura: notas para uma antropologia da sociedade contemporânea. Rio de Janeiro: Zahar; 1981.

15. Domingues RMSM, Dias MAB, Nakamura-Pereira M, Torres JA, d'Orsi E, Pereira APE, et al. Processo de decisão pelo tipo de parto no Brasil: da preferência inicial das mulheres à via de parto final. Cad Saúde Pública 2014; 30 Suppl 1:S101-16.

16. Carneiro RG. Cenas de parto e políticas de corpo: uma etnografia de práticas femininas de parto humanizado [Tese de Doutorado]. Campinas: Universidade Estadual de Campinas; 2011.
17. Hirsch ON. O "parto natural" e "humanizado" na visão de mulheres de camadas médias e populares no Rio de Janeiro. Civitas - Revista de Ciências Sociais 2015; 15:229.

18. Jordan B. Birth in four cultures: a crosscultural investigation of childbirth in Yucatan, Holland, Sweden and the United States. 4th Ed. Long Grove: Waveland Press; 1993.

19. Nakano AR, Bonan C, Teixeira LA. A normalização da cesárea como modo de nascer: cultura material do parto em maternidades privadas no Sudeste do Brasil. Physis (Rio J.) 2015; 25:885-904.

20. Fox NJ, Ward KJ, O'Rourke AJ. The expert patient: empowerment or medical dominance? The case of weight loss, pharmaceutical drugs and the internet. Soc Sci Med 2005; 60:1229309.

21. Louwen F, Daviss BA, Johnson KC, Reitter A. Does breech deliver in an upright position instead of on the back improve outcomes and avoid cesareans? Int J Gynecol Obstet 2017; 136:151-61.

22. Thomsen SR, Straubhaar JD, Bolyard D. Ethnomethodology and the study of online communities: exploring the cyber streets. Information Research 1998; 4(1). http://informationr. net/ir/4-1/paper50.html.

23. Heilborn ML, Sorj B. Estudos de gênero no Brasil - 1975-1995. In: Rodrigues C, Borges L, Ramos TRO, organizadores. Problemas de gênero. v. 1. Rio de Janeiro: Fundação Nacional de Artes; 2016; p. 75-104. 


\section{Abstract}

The aim of this paper is to comprehend the organisation of an online community which supports middle-class women from different parts of Brazil in the process of achieving humanized care in childbirth. A netnography has been performed in the community $\mathrm{C}$-section? Thanks, But No Thanks! on Facebook. The analysis focuses on knowledge exchange, mutual support among participants on what they call empowerment process and changes in physician-patient relationship. Four profiles have been categorized: uninitiated, initiated, informed patient and healthcare professional. The reasons why users search for online information encompass interest in decision-making autonomy, care and humanization of childbirth. The community contributes to this process as it organizes, educates and provides tools for participants transformation into informed patients.

Natural Childbirth; Humanization of Assistance; Online Social Networking; Patient Educations as Topic; Cultural Anthropology

\section{Resumen}

El propósito de este artículo es comprender la organización de una comunidad en línea cuyo objetivo es contribuir a la conquista del parto normal $y$ humanizado entre mujeres de clase media. Se realizó una netnografia en la comunidad ¿Cesárea? ¡No, Gracias! en la red social Facebook, cuyas participantes son de distintas partes de Brasil. El análisis enfoca el intercambio de saberes, apoyo mutuo entre las participantes sobre lo que denominan proceso de "empoderamiento" y cambios en la relación médico-paciente. Se categorizó cuatro perfiles de participantes: no iniciadas, iniciadas, paciente informada y profesional de salud. En las razones de las usuarias para la búsqueda de información en línea se incluye el interés por la autonomía de decisión, cuidado y humanización de la asistencia. La comunidad contribuye a ese proceso al organizar, educar y proporcionar herramientas para convertir a las participantes en pacientes informadas.

Parto Normal; Humanización de la Atención; Red Sociales en Linea; Educación del Paciente como Asunto; Antropología Cultural
Recebido em 12/Mar/2020

Versão final reapresentada em 14/Ago/2020

Aprovado em 17/Ago/2020 